\title{
Structure Design and Calibration of INS for Distributed POS Technology
}

\author{
Zhen Ma, Xiyuan Chen* \\ Key Laboratory of Micro-Inertial Instrument and Advanced Navigation Technology, Ministry of Education, School of Instrument \\ Science and Engineering, Southeast University, Nanjing 210096, China;
}

\begin{abstract}
With the development of science and technology, position and orientation system (POS) technology has become an important tool for airborne earth observation system, and plays an important role in both military and civil fields. The calibration of the device directly affects the accuracy of inertial navigation. Therefore, the paper designs a compact dual mode navigation system with high and low precision, which can be used in distributed POS system. Firstly, the status of IMU calibration technology is introduced. Then it introduces the working principle, structure design and layout design of fiber optic gyroscope (FOG) combination. Finally, the calibration experiment verifies that the designed FOG combination system meets the performance index.
\end{abstract}

\section{Introduction}

Airborne earth observation system is a kind of high-precision technical means to obtain space information with aircraft as observation platform, and it is an important means of military surveying and mapping and investigation. In order to compensate for the problems of image quality blurring and resolution reduction caused by gust disturbance and tremor, a position and attitude measurement system is needed. Distributed POS technology mainly consists of high-precision master POS and multiple small-sized IMU fixed on the task load. The transfer alignment filtering estimation of multiple sub IMU distributed on the flexible baseline is carried out by using the high-precision spatiotemporal measurement information from the main POS, so as to realize the accurate measurement of the flexible baseline multi node spatiotemporal reference [1-2]. The accuracy of inertial devices directly affects the measurement accuracy of distributed POS technology, so it is necessary to study the structure design and calibration of inertial devices. Researchers have done a lot of research on IMU calibration technology [3-6], and it can be seen that researchers use different methods to improve the calibration technology, which shows the importance of IMU calibration for INS. In order to provide high-precision navigation system for distributed POS, the paper designs the fiber optic gyroscope (FOG) integrated system. Firstly, the structure of the system is designed and analyzed, and then the IMU of the system is calibrated to verify the accuracy.

\section{Design of FOG combination}

\subsection{Structural design of FOG combination}

In the design of FOG combination, the power consumption, weight and cost are considered. The installation space of control system mounting bracket, FOG and accelerometer module is needed in the design of three-axis closed-loop FOG combination. The main body size is controlled within the range of $\Phi 130 \mathrm{~mm} \times 70 \mathrm{~mm}$. The size of a single accelerometer is $36 \mathrm{~mm} \times 24 \mathrm{~mm} \times 22.5 \mathrm{~mm}$, the interface and circuit board of accelerometer also need to leave space for installation. Moreover, after the assembly of the FOG assembly body structure, the center of mass is required to be in the center of the whole, which requires the structure to be very high.

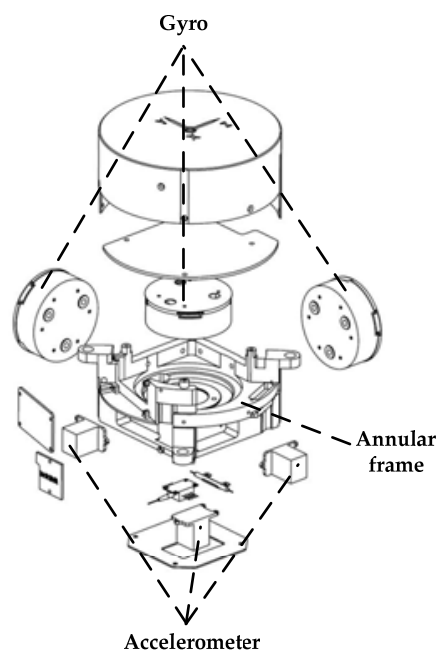

Fig.1. Spatial layout of FOG combined structure

\footnotetext{
${ }^{*}$ Corresponding author: chxiyuan@seu.edu.cn
} 
In order to meet the requirements of mechanical environment, this paper adopts structural integration design, and the structural design is shown in Fig. 1. In the FOG combination, there are three gyroscopes and three accelerometers in compact combination. Considering the overall weight and strength of the navigation system, the main material of the structure is made of 2A12-T4 aviation hard aluminum, which can meet the requirements of strength and stiffness, and reduce the overall weight. The deformation of this type of material in high and low temperature is small, which can effectively reduce the change of product's non orthogonal angle under high and low temperature.

\subsection{Layout design}

In the design process, in order to make the structure of FOG combination system more compact, the assembly mode in Fig. 6 is designed. Four damping rings are used at the contact position of fog combination and outer frame for damping. Two functional circuit boards are installed in the system, which are responsible for data acquisition, calculation, storage, external communication and power supply. In the installation box, the order from bottom to top is FOG combination, navigation system board, DSP core board and mounting shell. The base plate and the core board are connected with slots through pins, and the bottom plate is firmly fixed in the installation box through four screw fixing holes. The overall framework of the system is shown in Fig.2.
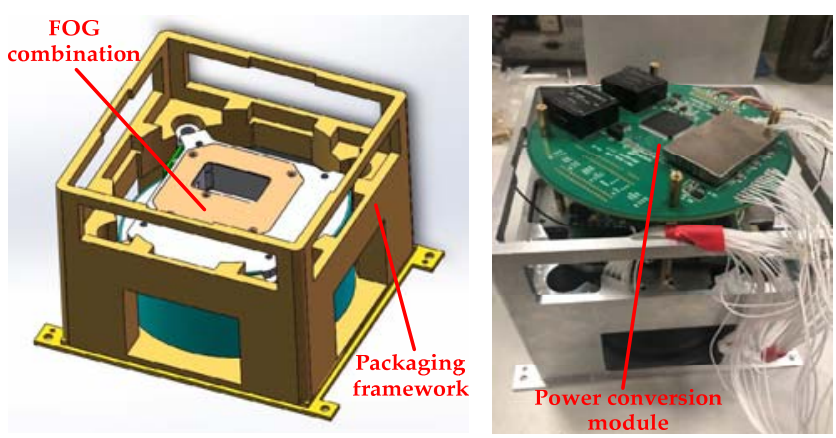

Fig.2. Schematic diagram of system structure layout

\section{Data analysis}

In the navigation system, due to the structural characteristics of inertial devices, the actual measured values often deviate from the real ideal values. If this kind of deviation is not suppressed or eliminated by technical means, it will accumulate with the inertial navigation integration algorithm, and the navigation system parameter estimation will appear serious drift phenomenon.

The errors of inertial devices are divided into installation error, zero drift error, magnetometer error and scale factor error. Among them, the output of gyroscope and accelerometer is digital signal or analog signal. These signals need to be converted by scale factor to get the actual angular velocity and acceleration physical output. Due to the influence of field measurement environment, the internal input and output responses of the device are inconsistent in different environments. The scale factor error is measured by percentage, and the unit is PPM. 1PPM means that the error between the measured scale value and the true value is within one millionth. The scale factor error of inertial devices can be expressed as follows.

$$
\delta \boldsymbol{K}=\left[\begin{array}{lll}
K_{x} & & \\
& K_{y} & \\
& & K_{z}
\end{array}\right]
$$

whrere, $K_{x}, K_{y}, K_{z}$ are the scale factor errors in the corresponding directions of inertial devices. Therefore, the IMU of the system is calibrated in the paper, and the experimental diagram is shown in Fig. 3.

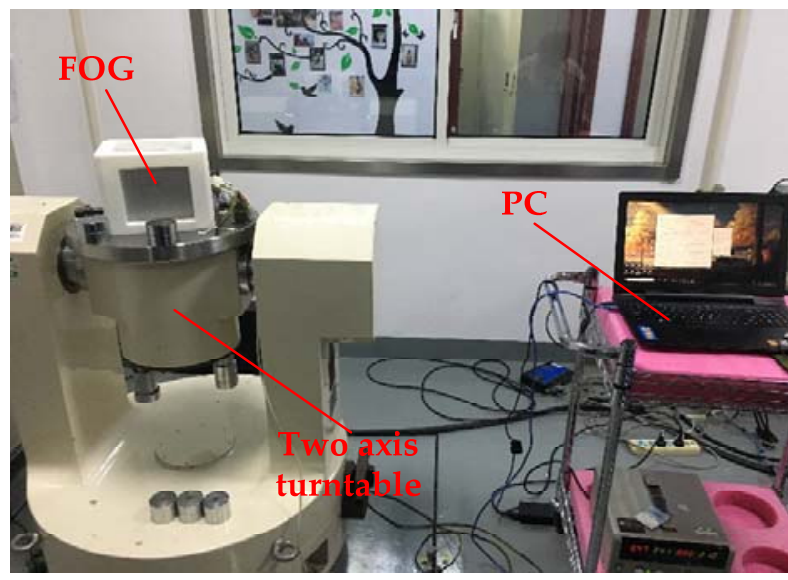

Fig. 3. Experimental diagram of double axis turntable

In the experiment, the attitude and position accuracy of the optical fiber IMU system are verified. The experimental verification is carried out in Shanghai Hengtong Optoelectronic Technology Co., Ltd., which has complete experimental equipment and can be used for experimental measurement. FOG combined system has two working modes. During the experiment, we first do the low precision attitude error compensation experiment, and then do the high precision attitude error compensation experiment. In the case of low precision pure inertial navigation, the measurement results of the first group of attitude error are shown in Fig. 4 and Tab.1. From the experimental results, we can conclude that the attitude errors of the low precision pure inertial navigation system after magnetic compensation are 0.1429 , 0.1218 and 0.4043 respectively after magnetic compensation. 

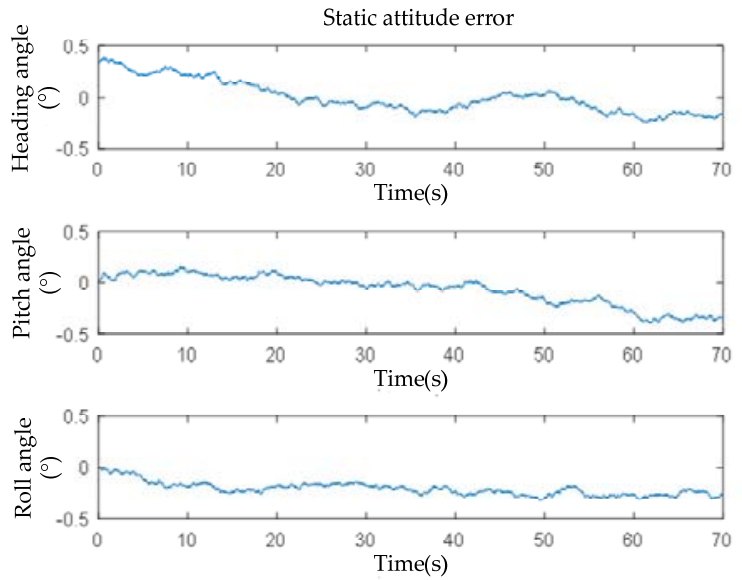

(a) Before magnetic compensation Static attitude error
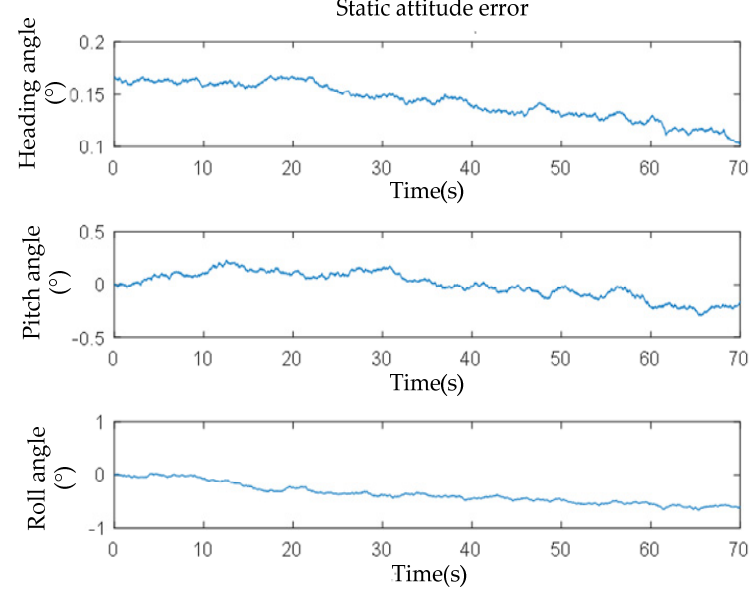

(b) After magnetic compensation

Fig.4. Static attitude error of low precision INS

Table 1. Static attitude error results.

\begin{tabular}{|c|c|c|c|}
\hline $\begin{array}{c}\text { Pure inertial } \\
\text { navigation }\end{array}$ & $\begin{array}{c}\text { Heading } \\
\text { angle error } \\
\left({ }^{\circ}, \mathbf{1 \sigma}\right)\end{array}$ & $\begin{array}{c}\text { Pitch error } \\
\left.\mathbf{(}^{\circ}, \mathbf{1 \sigma}\right)\end{array}$ & $\begin{array}{c}\text { Roll angle } \\
\text { error } \\
\left.\mathbf{(}^{\circ}, \mathbf{1 \sigma}\right)\end{array}$ \\
\hline $\begin{array}{c}\text { Before } \\
\text { magnetic } \\
\text { compensation }\end{array}$ & 0.1527 & 0.1617 & 0.2081 \\
\hline $\begin{array}{c}\text { After } \\
\text { magnetic } \\
\text { compensation }\end{array}$ & 0.1429 & 0.1218 & 0.4043 \\
\hline
\end{tabular}

In the case of low precision pure inertial navigation, the measurement results of the second group of attitude error are shown in Fig. 5 and Tab.2. From the experimental results, we can conclude that the heading angle error, pitch error and roll angle error of low precision pure inertial navigation system are $0.3181,0.1945$ and 0.2846 respectively after magnetic compensation.
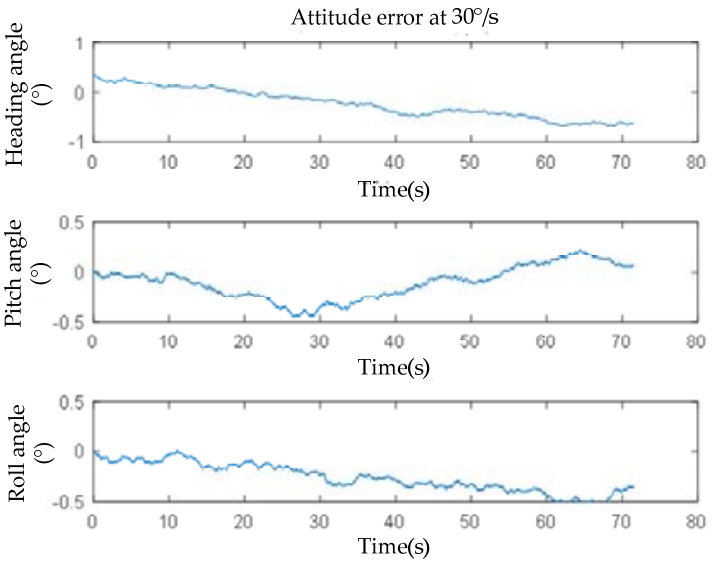

(a) Before magnetic compensation
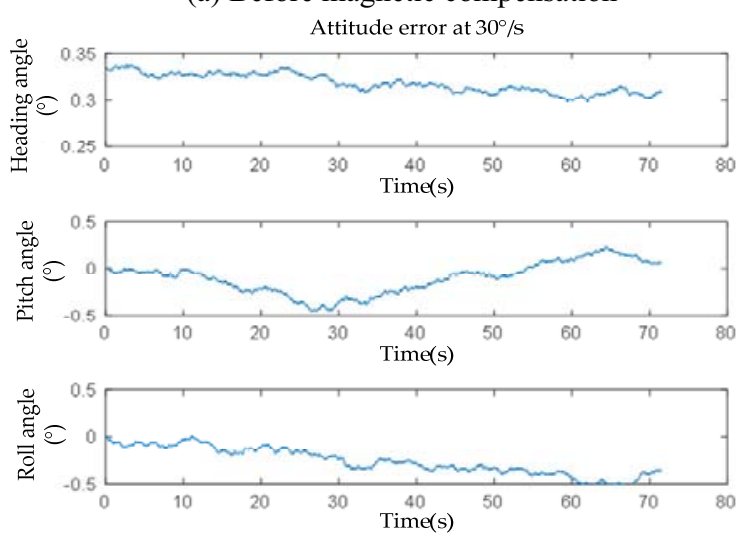

(b) After magnetic compensation

Fig.5. Attitude error of low precision INS at $30 \% \mathrm{~s}$ speed

Tab 2. Attitude error results at $30 \%$ s speed.

\begin{tabular}{|c|c|c|c|}
\hline $\begin{array}{c}\text { Pure inertial } \\
\text { navigation }\end{array}$ & $\begin{array}{c}\text { Heading } \\
\text { angle error } \\
\left({ }^{\circ}, \mathbf{1 \sigma}\right)\end{array}$ & $\begin{array}{c}\text { Pitch } \\
\text { error } \\
\left.\mathbf{(}^{\circ}, \mathbf{1 \sigma}\right)\end{array}$ & $\begin{array}{c}\text { Roll angle } \\
\text { error } \\
\left.\mathbf{(}^{\circ}, \mathbf{1 \sigma}\right)\end{array}$ \\
\hline $\begin{array}{c}\text { Before } \\
\text { magnetic } \\
\text { compensation }\end{array}$ & 0.3573 & 0.1982 & 0.2998 \\
\hline $\begin{array}{c}\text { After } \\
\text { magnetic } \\
\text { compensation }\end{array}$ & 0.3181 & 0.1945 & 0.2846 \\
\hline
\end{tabular}

In the case of high-precision pure inertial navigation, the measurement results of the first group of attitude errors are shown in Fig. 6 and Tab.3. From the experimental results, we can conclude that the heading angle error, pitch error and roll angle error of the high-precision pure inertial navigation system are $0.003,0.003$ and 0.004 respectively after compensating the bias. 

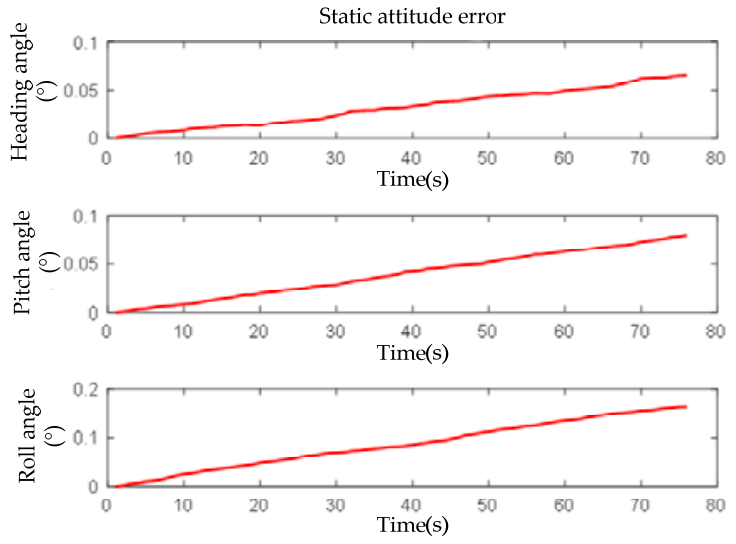

(a) Before bias compensation
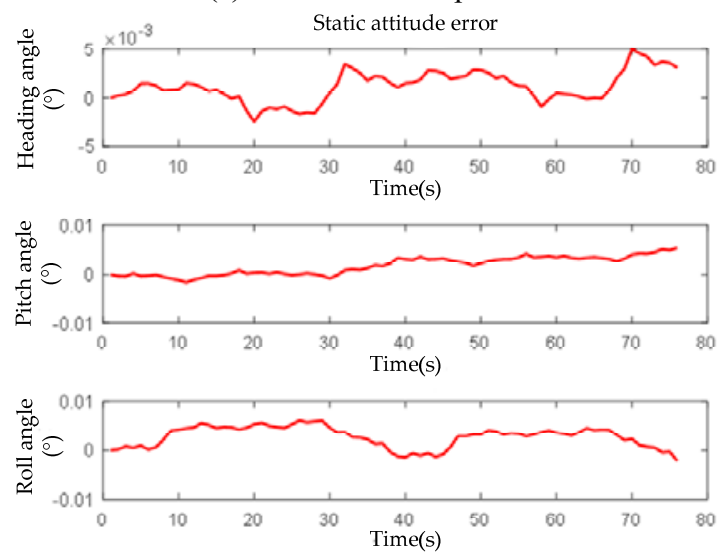

(b) After bias compensation

Fig.6. Static attitude error of high precision INS

Tab 3. Static attitude error results.

\begin{tabular}{|c|c|c|c|}
\hline $\begin{array}{c}\text { Pure inertial } \\
\text { navigation }\end{array}$ & $\begin{array}{c}\text { Heading } \\
\text { angle error } \\
\left({ }^{\circ}, \mathbf{1} \boldsymbol{\sigma}\right)\end{array}$ & $\begin{array}{c}\text { Pitch error } \\
\left.\mathbf{(}^{\circ}, \mathbf{1} \boldsymbol{\sigma}\right)\end{array}$ & $\begin{array}{c}\text { Roll angle } \\
\text { error } \\
\left({ }^{\circ}, \mathbf{1} \boldsymbol{\sigma}\right)\end{array}$ \\
\hline $\begin{array}{c}\text { Before manual } \\
\text { compensation } \\
\text { of bias }\end{array}$ & 0.037 & 0.046 & 0.098 \\
\hline $\begin{array}{c}\text { After manual } \\
\text { compensation } \\
\text { of bias }\end{array}$ & 0.003 & 0.003 & 0.004 \\
\hline
\end{tabular}

In the case of high-precision pure inertial navigation, the measurement results of the second group of attitude errors are shown in Fig. 7 and Tab.4. From the experimental results, we can conclude that the heading angle error, pitch error and roll angle error of the high-precision pure inertial navigation system are $0.004,0.078$ and 0.125 respectively after compensating the bias.
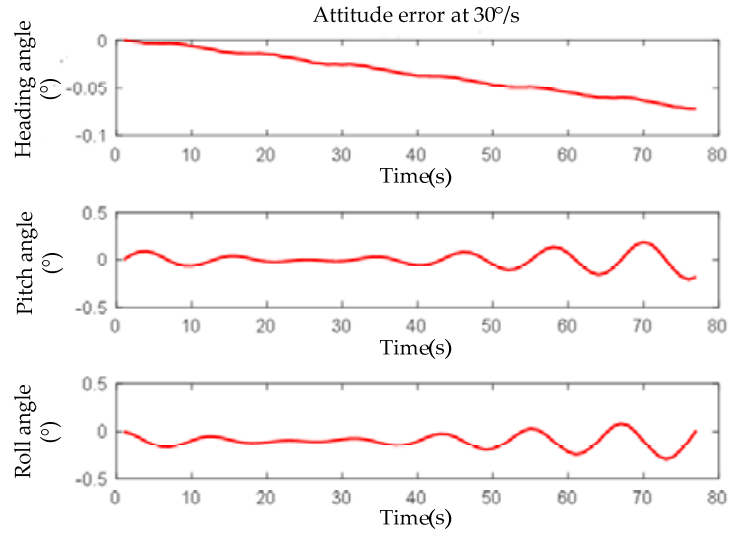

(a) Before bias compensation
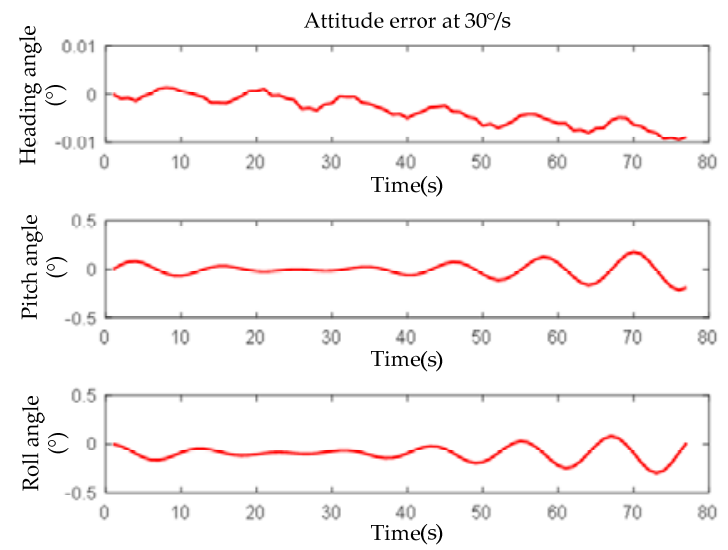

(b) After bias compensation

Fig.7. Attitude error of high precision INS at $30 \%$ s speed

Tab.4. Attitude error results at $30 \%$ s speed.

\begin{tabular}{|c|c|c|c|}
\hline $\begin{array}{c}\text { Pure inertial } \\
\text { navigation }\end{array}$ & $\begin{array}{c}\text { Heading } \\
\text { angle error } \\
\left({ }^{\circ}, \mathbf{1 \sigma}\right)\end{array}$ & $\begin{array}{c}\text { Pitch } \\
\text { error } \\
\left(^{\circ}, \mathbf{1 \sigma}\right)\end{array}$ & $\begin{array}{c}\text { Roll angle } \\
\text { error } \\
\left({ }^{\circ}, \mathbf{1 \sigma}\right)\end{array}$ \\
\hline $\begin{array}{c}\text { Before } \\
\text { manual } \\
\text { compensation } \\
\text { of bias }\end{array}$ & 0.041 & 0.079 & 0.126 \\
\hline $\begin{array}{c}\text { After manual } \\
\text { compensation } \\
\text { of bias }\end{array}$ & 0.004 & 0.078 & 0.125 \\
\hline
\end{tabular}

\section{Conclusion}

In this paper, a kind of fog combined system is designed. Firstly, the structure design is analyzed, and then the IMU calibration experiment of FOG combined system is carried out. The experimental results show that the accuracy after error compensation is less than $0.5^{\circ}$ and meets the requirements of working performance. It should be noted that the sampling time of static and dynamic experiments under high and low precision is less than 80s. The sampling time is short, and the error under long working time needs further verification. 


\section{Acknowledgements}

This work was supported by the National Natural Science Foundation of China (No. 61873064 and No. 51375087) and the Scientific Research Foundation of Graduate School of Southeast University (No. YBPY1982).

\section{Reference}

1. J. C. Fang, Z. C. Liu, IEEE Sensors J., 15, 6 (2015)

2. J. L. Li, F. Jiao, J. C. Fang, IEEE Transactions on Instrumentation and Measurement, 62, 2 (2013)

3. H. Zhang, Y. Wu, W. Wu, Measurement Science and Technology, 21, 1 (2010)

4. F. Wang, J. Cao, M. Wu, International conference on information and automation, (2016)

5. J.J. Balamuta, R. Molinari, S. Guerrier, IEEE Sensors Journal, 18, 4 (2017)

6. K. Draganová, P. Lipovský, M. Šmelko, 2018 XIII International Scientific Conference-New Trends in Aviation Development. (2018) 